\title{
Fascial Organisation and Lymphatic Systems Around the Pelvic Floor: A Literature Review
}

\author{
KENTARO SATO ${ }^{1,2}$, TAKUYA MIURA ${ }^{1}$, YOSHIYUKI SAKAMOTO ${ }^{1}$, \\ HAJIME MOROHASHI ${ }^{1}$ and KENICHI HAKAMADA ${ }^{1}$ \\ ${ }^{1}$ Department of Gastroenterological Surgery, Hirosaki University, Graduate School of Medicine, Aomori, Japan; \\ ${ }^{2}$ Department of Gastroenterological Surgery, Hakodate Municipal Hospital, Hokkaido, Japan
}

\begin{abstract}
This review summarises the anatomy and lymphatic systems around the pelvic floor. We investigated the lymphovascular network in the anorectal region, focusing on the hiatal ligament, which comprises smooth muscle fibres derived from the longitudinal muscle and connecting the anal canal and coccyx, and the endopelvic fascia, which seems to comprise collagen and elastic fibres. During rectal surgery, endopelvic fascia is recognized as a sheet of fascia covering the levator ani muscle. Endopelvic fascia is extensively attached to the smooth muscle fibres diverging from the longitudinal muscle of the rectum. Analysis of the lymphovascular network using submucosal India ink injection and indocyanine green fluorescence imaging suggests a functional lymphatic flow between rectal muscle fibres and hiatal ligament and endopelvic fascia. Precise analysis of the lymphatic systems of fascial organization around the pelvic floor may be useful in formulating therapeutic strategies for low rectal cancer.
\end{abstract}

To date, only few studies have attempted a macroscopic analysis of the lymphatic systems in the anorectal region (1). Several microanatomical studies of this region have revealed muscular and fascial structures, including the levator ani muscle (LAM), hiatal ligament (HL), endopelvic fascia (EF), and Denonvilliers' fascia (DVF) (2-9), but details of the lymphatic drainage in this region have not been reported.

This article is freely accessible online.

Correspondence to: Kenichi Hakamada, Department of Gastroenterological Surgery, Hirosaki University Graduate School of Medicine, 5 Zaifu-cho, Hirosaki, Aomori 036-8562, Japan. E-mail: hakamada@hirosaki-u.ac.jp

Key Words: Anal canal, anatomy, indocyanine green, lymphatic system, rectum, review.
Understanding the lymphatic system in the anorectal region can provide important information regarding therapeutic strategies for low rectal cancer. Abdominoperineal resection (APR) showed poorer outcomes than sphincter-preserving procedures in previous studies $(10,11)$. Although the reason for the difference in outcome between abdominoperineal resection and sphincter-preserving procedures is controversial and a selection bias may have existed in those studies, several therapeutic strategies, such as enlarging the resection area (12), preoperative chemotherapy (13) and chemoradiotherapy $(14,15)$ have been evaluated. On the other hand, local excision has been attempted for early low rectal cancer because low anterior resection and intersphincteric resection (ISR) have the risks of anastomotic leakage and permanent stoma, especially in male patients (16). Although the quality of life following local excision is satisfactory, its oncological safety remains controversial. Moreover, the recurrence rate after local excision is higher than that after total mesorectal excision $(17,18)$. Although local excision with adjuvant radiotherapy and chemoradiotherapy are currently performed $(19,20)$, the appropriate indications for these modalities remain debatable. Thus, investigating the lymphatic system of the anorectal region may provide useful information for developing therapeutic strategies for early and advanced low rectal cancer. This study reviewed previous analyses of the anatomical structures and lymphatic systems of the anorectal region, especially of the pelvic floor and the surrounding structures, including the LAM, HL, EF, DVF, and lateral ligament. We also reviewed our previous study, which investigated the lymphovascular network and tissue drainage in the anorectal region using India ink injections, immunohistochemistry, and intraoperative indocyanine green (ICG) - fluorescence imaging (FI) (21). This literature review aimed to clarify the anatomical structures around the pelvic floor. We discussed the scope of future studies required to develop adequate therapeutic strategies for low rectal cancer. 


\section{Fascial Structures and Lymphatic Distributions}

$H L$ and EF. The HL is usually a thick white bundle on the surface of the LAM in the posterior portion of the anal canal (2), which mainly consists of smooth muscles $(3,4,7)$. Kinugasa et al. reported a similar structure, known as the "ventral layer of the anococcygeal ligament," comprising abundant smooth muscle and elastic fibres and connecting the anal canal and coccyx between bilateral slings of the LAM (3). This structure seems to be corresponding to "anococcygeal raphe" that Shafik et al. reported (2). Tsukada et al. reporting the detailed muscular anatomy around the LAM described the presence of a thick tissue on the surface of the LAM, comprising smooth muscle fibres and continuing to the longitudinal muscle (7). This thick fascia filled the gap between the LAM and a longitudinal muscle, which corresponded to the HL. Thus, HL may comprise smooth muscle fibres derived from the longitudinal muscle. Generally, EF represents a sheet of fascia lining the pelvic walls and floor and covering the obturator internus, piriformis, LAM, and coccygeus muscles (22). However, its interpretation varies among colorectal surgeons, gynecologists, and urologists. Moreover, EF has many synonyms, including lateral pelvic fascia, superior pelvic fascia, parietal pelvic fascia, levator fascia, and parapelvic fascia (22). These variations in interpretation and the several synonyms have caused confusion.

Colorectal surgeons usually identify EF intraoperatively as the fascia on the surface of LAM. In the pelvic floor, this fascia is regarded as the parietal peritoneum, whereas the prostatic fascia corresponds to the visceral peritoneum (23, 24). This review focuses on the fascia covering the LAM, which is defined as the EF by colorectal surgeons.

Elastic and collagen fibres are the main components of the EF (25). In the region around the LAM, the border between the fibres of the EF and smooth muscle fibres from the rectal longitudinal muscle is unclear. Several studies have reported a structure corresponding to the EF that covers the LAM. Arakawa et al. reported that the LAM was covered with fascia composed of smooth muscles, which merged to form the external rectal muscularis propria (6). Macchi et al. reported that the longitudinal anal muscle originates from the LAM and the longitudinal muscle of the rectum and interposes between the internal and external anal sphincters (5). Immunohistochemical staining demonstrated mixed skeletal muscle and smooth muscle fibres around the LAM. Tsukada et al. reported that smooth muscle fibres continued from the longitudinal muscle and were directly attached to the LAM as an indentation in the lateral and anterolateral portions (7).

Thus, the original EF seems to comprise collagen and elastic fibres; the attachment of smooth muscle from the longitudinal muscle to the EF may spread relatively extensively on the surface of the LAM. Conversely, HL consists mainly of smooth muscle; therefore, HL and EF seem to be separate structures. As described above, previous studies on HL and EF only examined muscular structures because of their importance in low rectal cancer surgery, especially in sphincter-preserving procedures such as ISR. These studies demonstrated an interaction between smooth muscle fibres from the longitudinal muscle, HL, and EF. Analyses of the microanatomical lymphovascular network in these areas could explain the low rectal cancer spread around the pelvic floor, further facilitating the development of therapeutic strategies and surgical procedures that improve oncological safety. During ISR, the HL is cut and retained in the unresected area. Moreover, smooth muscle fibres from the rectal longitudinal muscle seem to attach to the LAM in an indented manner or mix with the EF. Therefore, tumours may spread extensively around the LAM through these smooth muscle fibres.

DVF. Denonvilliers first described the DVF in 1836 (26). The DVF separates the rectum from the bladder and seminal vesicles in men and the cervix and vagina in women (27). In women, the DVF is occasionally referred to as the rectovaginal septum (28). The DVF is traditionally regarded as a fusion fascia (29); however, Kim et al. described the DVF as a tension-induced structure, rather than a fusion fascia (8). These authors suggested that the DVF develops in later stages of foetal development, from mechanical stress, due to the increased volume of surrounding organs.

Many studies have thoroughly examined the microanatomical fascial structures of the DVF. The structure mainly comprises multiple fascial condensations of collagen and smooth muscle fibres (9). Kinugasa et al. reported that the DVF is single-layered in the centre and divides into 2-3 layers laterally on both sides, ending in neurovascular bundles and extending to the posterolateral side, separating the neurovascular bundle from the mesorectum (30). Similarly to the HL and EF, the lymphatic systems of the DVF have not been studied.

Lateral ligament. The lateral ligament comprises a broad band of dense connective tissue that passes toward and outward from the lateral walls of the rectum toward the base of the bladder at the termination point of the ureters (31). However, the existence of the lateral ligament is controversial because this ligament was not detected in some cadaveric specimens $(32,33)$. Goligher identified the lateral ligament after dissecting the anterior and posterior portions of the rectum (34). Anatomical analyses of the lateral ligament, including its lymphatic drainage, have been performed. According to the studies, the middle rectal artery runs from the lower mesorectum to the lateral pelvic wall 
through the lateral ligament (31), and the lymphatic flow seems to run alongside this artery (1). However, Sato et al. reported that the middle rectal artery was observed in only $22 \%$ of cases (35). Pak-art et al. reported that no artery was found histologically in any lateral ligament (36). Moreover, studies on the lymphatic flow of the lateral ligament were mainly based on the macroscopic anatomy and on speculations from the clinical metastatic features $(1,31)$. Yanagita et al. suggested the existence of lymph node metastatic pathways between the pararectal and lateral regions, using the isotope method (37). However, this study did not indicate whether the pathway involved the lateral ligament or whether it involved the lateral ligament and other pathways.

\section{Functional Analyses of Lymphatic Flow}

Lymphatic tracer injection. Lymphatic tracer injection has been used for decades. Jamieson et al. injected Prussian blue dye into cadavers and analysed the macroscopic distribution of the lymphatic ducts of the colon (38). Submucosal injections of carbon particles and India ink have been used as preoperative markings in laparoscopic colorectal surgery $(39,40)$. Recently, this method was applied for the detection of sentinel, regional, and metastatic lymph nodes (41-43). Additionally, Gao et al. examined the barrier of lymphatic flow between the visceral and parietal fascia of the colon by injecting carbon nanoparticles subserosally during surgery (44). Thus, the lymphatic flow in the colon has been well studied.

However, studies that examined the lymphatic systems in the anorectal region using lymphatic tracers are lacking due to observation difficulties. Macroscopic examination of the lymphatic systems in the lower rectum and anal canal using lymphatic tracers was first established by Blair et al. (1). These authors demonstrated the lymphatic flow pattern in the anorectal region, such as the lymphatic flow running with the superior rectal vessels, with the middle rectal vessels to the hypogastric nodes, and with the inferior rectal vessels to the hypogastric nodes. Block et al. injected a sky blue solution into the rectal wall and demonstrated extensive lymphatic communication between the lower rectum and surrounding tissues, such as the route along the LAM (45). Presumptions about the lymphatic flow in the anorectal region were made in these studies based on the distribution of dyed lymphatic ducts from macroscopic analyses. Kumashiro et al. injected carbon particles into pedal lymphatic ducts and demonstrated lymphatic pathways between the inguinal, lateral, and para-aortic regions (46). The authors also made speculations based on the distribution of black-dyed lymphatic nodes. Lymphatic flow in the anorectal region is assumed to be complicated; therefore, only examining dyed lymph nodes seems insufficient. Microanatomical examinations of the actual flow of lymphatic tracers into lymphatic ducts in the pelvic floor, including those in the HL, EF, LAM, lateral region, and inguinal region, are essential to analyse functional lymphatic systems. However, such studies have not yet been conducted.

Isotope methods. In 1977, Bartholdson et al. reported radioisotope injection into the rectal submucosa (47). The authors used gold $198(198 \mathrm{Au})$ and reported that $<1 \%$ of the isotope drained into the pelvic lymph nodes when the radioisotope was injected into the upper and middle rectum. Takemura et al. injected technetium-99m (99mTc) into the submucosa on the dentate line and demonstrated that the lateral pelvic lymph nodes (LPLNs), especially obturator lymph nodes, had higher accumulation of the radioisotope than the mesenteric lymph nodes (48). Funahashi et al. demonstrated two types of lymphatic drainage routes in advanced low rectal cancer using $99 \mathrm{mTc}$. These routes were the lateral and mesorectal drainage routes (49). Recently, Yanagita et al. reported the utility of the radioisotope method by the submucosal injection of $99 \mathrm{mTc}$ to detect metastatic LPLNs in low rectal cancer cases (37). Thus, radioisotope methods have been used to examine lateral lymphatic drainage from the lower rectum. However, recently, ICG-FI emerged as an alternative examination method because of its ease of use.

ICG-FI. Currently, ICG-FI is the most commonly used method for intraoperative lymph node mapping in colorectal cancer. Few ICG injection-related adverse effects have been reported (50), and their management is easier than that of radioisotope-related adverse effects. Furthermore, recent laparoscopic systems with near-infrared camera systems permit relatively easy performance of ICG-FI by colorectal surgeons.

ICG-FI is mainly used for lymph node mapping in the mesocolon and mesorectum (51-55). A systematic review and meta-analysis demonstrated that the median sensitivity and specificity of malignant lymph node detection using ICG-FI in colorectal cancer were $73.7 \%$ and $100 \%$, respectively (50).

Lymph node mapping using ICG-FI for low rectal cancer has also been attempted. Several studies have examined the lymphatic flow from the lower rectum to LPLNs $(56,57)$. Noura et al. reported that sentinel LPLNs were successfully identified in $92 \%$ of cases (56). Zhou et al. reported a significantly larger number of harvested LPLNs in a group of patients who underwent ICG-FI compared to another group of patients that did not undergo ICG-FI (57). Thus, intraoperative ICG-FI seems useful for detecting lymphatic pathways between the lower rectum and the lateral region. Furthermore, real-time ICG-FI could detect the actual lymphatic flow pathways between the lower rectum and the lateral region. 
Table I. Review of anatomical studies of pelvic floor around the anorectal region.

\begin{tabular}{|c|c|c|c|c|c|c|}
\hline Author (ref.) & Years & Study design & Materials & Methods & Staining & Key findings \\
\hline Shafik et al. (2) & 1999 & $\begin{array}{l}\text { Descriptive } \\
\text { study }\end{array}$ & $\begin{array}{l}\text { Cadavers } \\
(\mathrm{n}=23)\end{array}$ & $\begin{array}{l}\text { Microscopic } \\
\text { examination }\end{array}$ & $\begin{array}{l}\text { Hematoxylin-eosin staining } \\
\text { and Verhoe-van Gieson staining }\end{array}$ & $\begin{array}{l}\text { •Posterior portion: presence } \\
\text { of the "anococcygeal raphe", } \\
\text { thick fascial bandle connecting } \\
\text { between rectum and coccyx }\end{array}$ \\
\hline Kinugasa et al. (3) & 2011 & $\begin{array}{l}\text { Descriptive } \\
\text { study }\end{array}$ & $\begin{array}{c}\text { Cadavers } \\
(\mathrm{n}=20) \text { and } \\
\text { fresh cadavers } \\
\qquad(\mathrm{n}=6)\end{array}$ & $\begin{array}{l}\text { Macroscopic } \\
\text { and } \\
\text { microscopic } \\
\text { examination }\end{array}$ & $\begin{array}{l}\text { Masson-Trichrome staining } \\
\text { and aldehyde-fuchsin staining }\end{array}$ & $\begin{array}{l}\text {-Posterior portion: presence of } \\
\text { the "ventral layer of the } \\
\text { anococcygeal ligament", } \\
\text { comprising abundant smooth } \\
\text { muscle and elastic fibres and } \\
\text { connecting the anal canal and } \\
\text { coccyx between bilateral } \\
\text { slings of the LAM }\end{array}$ \\
\hline Muro et al. (4) & 2014 & $\begin{array}{l}\text { Descriptive } \\
\text { study }\end{array}$ & $\begin{array}{l}\text { Cadavers } \\
(\mathrm{n}=14)\end{array}$ & $\begin{array}{l}\text { Macroscopic } \\
\text { and } \\
\text { Microscopic } \\
\text { examination }\end{array}$ & $\begin{array}{l}\text { Hematoxylin-eosin staining, } \\
\text { Elastica van Gieson staining } \\
\text { and immunohistochemistry, } \\
\text { for smooth and skeltal muscle }\end{array}$ & $\begin{array}{l}\text {-Posterior portion: presence of } \\
\text { a thick white fibrous bundle } \\
\text { extending from the rectum to } \\
\text { the coccyx, comprising } \\
\text { smooth muscle fibres }\end{array}$ \\
\hline Macchi et al. (5) & 2008 & $\begin{array}{l}\text { Descriptive } \\
\text { study }\end{array}$ & $\begin{array}{c}\text { Cadavers } \\
(\mathrm{n}=16)\end{array}$ & $\begin{array}{l}\text { Microscopic } \\
\text { examination }\end{array}$ & $\begin{array}{l}\text { Hematoxylin-eosin staining, } \\
\text { azan-Mallory staining, } \\
\text { Weigert's staining, and } \\
\text { immunohistochemistry for } \\
\text { smooth and skeltal muscle }\end{array}$ & $\begin{array}{l}\text {-Presence of the "longitudinal } \\
\text { anal muscle" which } \\
\text { mainly composed of } \\
\text { outer striated muscle fibres } \\
\text { and small numbers of inner } \\
\text { smooth muscle fibres, } \\
\text { originate from the LAM and } \\
\text { the longitudinal muscle } \\
\text { of the rectum }\end{array}$ \\
\hline Arakawa et al. (6) & 2004 & $\begin{array}{l}\text { Descriptive } \\
\text { study }\end{array}$ & $\begin{array}{c}\text { Cadavers } \\
(\mathrm{n}=46)\end{array}$ & $\begin{array}{l}\text { Microscopic } \\
\text { examination }\end{array}$ & $\begin{array}{l}\text { Hematoxylin-eosin staining, } \\
\text { Azan staining, aldehyde-fuchsin } \\
\text { staining, and immunohistochemistry } \\
\text { for smooth muscle }\end{array}$ & $\begin{array}{l}\text {-Variations in the interface } \\
\text { between the LAM and } \\
\text { the rectal muscularis propria } \\
\text { Exsitence of the covering } \\
\text { fascia of the LAM changed } \\
\text { abruptly into smooth muscles, } \\
\text { which merged into the external } \\
\text { rectal muscularis propria. }\end{array}$ \\
\hline Tsukada et al. (7) & 2016 & $\begin{array}{l}\text { Descriptive } \\
\text { study }\end{array}$ & $\begin{array}{l}\text { Cadavers } \\
(\mathrm{n}=5) \text { and } \\
\text { specimens of } \\
\text { APR }(\mathrm{n}=13)\end{array}$ & $\begin{array}{l}\text { Microscopic } \\
\text { examination }\end{array}$ & $\begin{array}{l}\text { Hematoxylin-eosin staining, } \\
\text { Elastica van Gieson staining, } \\
\text { and immunohistochemistry } \\
\text { for smooth and skeltal muscle }\end{array}$ & $\begin{array}{l}\text {-Posterior portion: presence of } \\
\text { a thick tissue on the surface of } \\
\text { the LAM, comprising smooth } \\
\text { muscle fibres and continuing to } \\
\text { the longitudinal muscle } \\
\text {-Lateral and anterolateral } \\
\text { portion: smooth muscle fibres } \\
\text { continued from the longitudinal } \\
\text { muscle and were directly } \\
\text { attached to the LAM } \\
\text { as an indentation }\end{array}$ \\
\hline Sato et al. (21) & 2021 & $\begin{array}{l}\text { Descriptive } \\
\text { study }\end{array}$ & $\begin{array}{l}\cdot \text { Fresh cadaver } \\
(\mathrm{n}=1) \text { and specimens } \\
\text { of APR }(\mathrm{n}=6) \\
\cdot \text { Patients underwent } \\
\text { surgery for low } \\
\text { rectal cancer }(\mathrm{n}=4)\end{array}$ & $\begin{array}{l}\text {-India Ink } \\
\text { injection } \\
\text { and } \\
\text { microscopic } \\
\text { examination } \\
\text {-Intraoperative } \\
\text { ICG-FI }\end{array}$ & $\begin{array}{l}\text { Hematoxylin-eosin staining, } \\
\text { silver impregnation staining, } \\
\text { and immunohistochemistry for } \\
\text { lymphatic duct and blood vessel }\end{array}$ & $\begin{array}{l}\text { •Posterior portion: functional } \\
\text { lymphovascular flow between } \\
\text { the rectal longitudinal muscle } \\
\text { fibres and the HL } \\
\text {-Lateral portion: functional } \\
\text { lymphovascular flow from } \\
\text { the anal canal to the surface of } \\
\text { the LAM through longitudinal } \\
\text { muscle fibres extending } \\
\text { to the EF }\end{array}$ \\
\hline
\end{tabular}


Table I. Continued

\begin{tabular}{|c|c|c|c|c|c|c|}
\hline Author (ref.) & Years & Study design & Materials & Methods & Staining & Key findings \\
\hline $\begin{array}{l}\text { Raychaudhuri } \\
\text { et al. (22) }\end{array}$ & 2008 & $\begin{array}{l}\text { Literature } \\
\text { review }\end{array}$ & - & - & - & $\begin{array}{l}\text { •EF represents a sheet of fascia } \\
\text { lining the pelvic walls and floor } \\
\text { and covering the obturator } \\
\text { internus, piriformis, LAM, } \\
\text { and coccygeus muscles }\end{array}$ \\
\hline Cör et al. (25) & 2003 & $\begin{array}{l}\text { Descriptive } \\
\text { study }\end{array}$ & $\begin{array}{c}\text { Female patients } \\
\text { underwent } \\
\text { gynaecologic surgical } \\
\text { procedures and } \\
\text { biopsies from } \\
\text { the } \mathrm{EF}(\mathrm{n}=54)\end{array}$ & $\begin{array}{l}\text { Microscopic } \\
\text { examination }\end{array}$ & $\begin{array}{l}\text { Hematoxylin-eosin staining, } \\
\text { Masson-Trichrome staining, } \\
\text { Weigert's staining, and } \\
\text { immunohistochemistry for } \\
\text { collagen type I and type III }\end{array}$ & $\begin{array}{l}\text {-Elastic and collagen fibres are } \\
\text { the main components of the EF } \\
\text {-Quantity of elastic and collagen } \\
\text { fibres in the EF does not } \\
\text { play a significant } \\
\text { role in continence }\end{array}$ \\
\hline
\end{tabular}

LAM: Levator ani muscle; APR: abdominoperineal resection; ICG-FI: indocyanine green fluorescence imaging; HL: hiatal ligament; EF: endopelvic fascia.

However, examination of lymphatic flow between the anorectal region and pelvic floor structures, such as the HL, $\mathrm{EF}$, and LAM, using intraoperative ICG-FI has not been reported. To our knowledge, this is the first study to examine these areas using ICG-FI. ICG-FI seems to be the most reasonable method for examining lymph flow around the pelvic floor because this area is clearly visualised during laparoscopic surgery. Further studies on the pelvic floor using ICG-FI are required.

\section{Our Novel Findings of the Anorectal Lymphatic System}

Our observational study attempted to demonstrate functional anorectal lymphovascular networks (21). We performed histological examinations using a combination of immunohistochemistry, India ink injection in fresh cadavers and abdominoperineal resection specimens, and intraoperative ICG-FI in low rectal cancer cases.

Submucosal India ink injection on the dentate line and immunohistochemical analyses demonstrated the distribution of lymphatic ducts and vasculature, suggesting tissue drainage and a functional lymphovascular network around the LAM. India ink deposition was detected in the venous lumina and surrounding stroma of the rectal wall, and in the $\mathrm{HL}$ and smooth muscle fibres from the longitudinal muscle extending to the EF. These results are presented as figures in our published article (21).

ICG-FI demonstrated tissue fluid flow around the pelvic floor. ICG fluorescence was detected in both the caudal portion of the HL (Figure 1A, B) and the lateral and anterolateral sites of the EF (Figure 1D-F), with band-like structures connecting the LAM. Figure 2 shows the schemas of lymphovascular flow around the anal canal illustrated from the results of our analyses. The illustrated lymphovascular flow may overlap the fascial structures of the pelvic floor from previous studies that reported that smooth muscle fibres from the longitudinal muscle may spread on the surface of the LAM attaching with EF and that HL may comprise smooth muscle fibres derived from the longitudinal muscle (Figure 2C).

\section{Summary and Expected Future Perspectives}

This literature review summarised the anatomy and lymphatic systems around the pelvic floor. Table I shows the key anatomical studies of pelvic floor around the anorectal region. Although our data do not completely prove the existence of functional lymphatic flow in the anorectal region, the localisation of lymphatic vessels in this area and the migration of lymphatic tracers in the interstitial tissue strongly suggest the presence of lymphatic flow. Moreover, the ICG-FI suggests lymphatic flow between rectal muscle fibres, HL, and EF.

Considering from this review, enlarging the resection area of APR including the EF and HL seem to be effective. In addition, this review may provide important information about the oncological safety of ISR. Generally, during ISR, smooth muscle fibres from the longitudinal muscles are not resected. However, Denost et al. reported that the resection line of transanal ISR is posterior to the pelvic sheath, and that transanal ISR enables EF resection (58). In low rectal cancer cases where the invasion depth may reach the longitudinal muscle, HL and EF resection, as well as preoperative therapy, may be useful. Likewise, the higher recurrence rates observed in local excision than in total mesorectal excision may be explainable by the widespread lymphovascular network between the rectal wall and EF, and HL. 
A

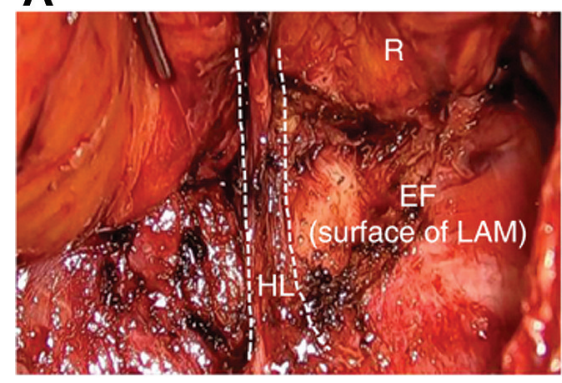

B

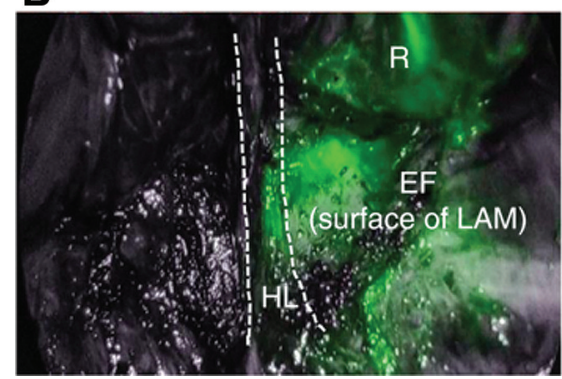

C

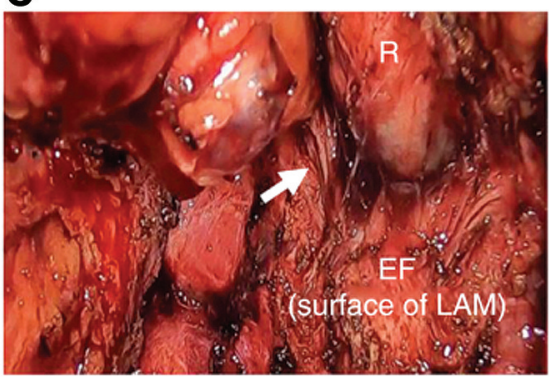

D

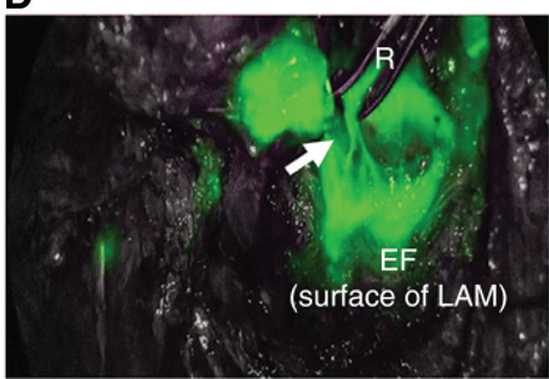

E

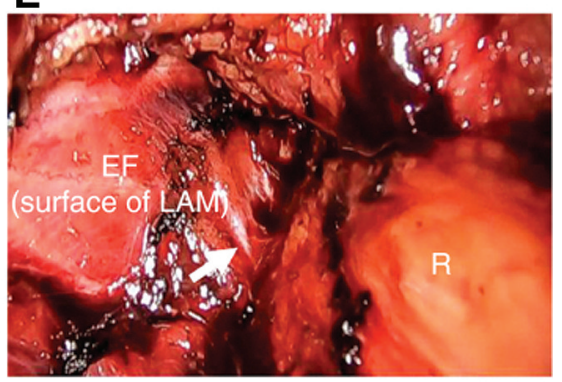

$\mathbf{F}$

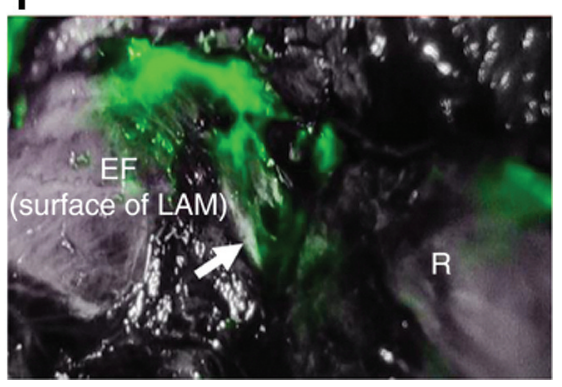

Figure 1. ICG-FI findings in a 57-year-old man with low rectal cancer. $(A, B)$ Images of the posterior wall before the dissection of the HL (surrounded by dotted lines). (C, D) Images of the posterior wall after HL dissection. (E, $F)$ Images of the left lateral and anterolateral walls. (B) Lymphatic flow (green) is observed in the deep part of the HL. (D, F) Lymphatic flow is observed from the muscular layers of the anal canal to the surface of the LAM (endopelvic fascia) through the longitudinal muscle fibres (white arrow). (B, D, F) Near-infrared images. EF, Endopelvic fascia; $H L$, hiatal ligament; ICG-FI, indocyanine green fluorescence imaging; LAM, levator ani muscle; $R$, rectum. Figures are cited from (21).
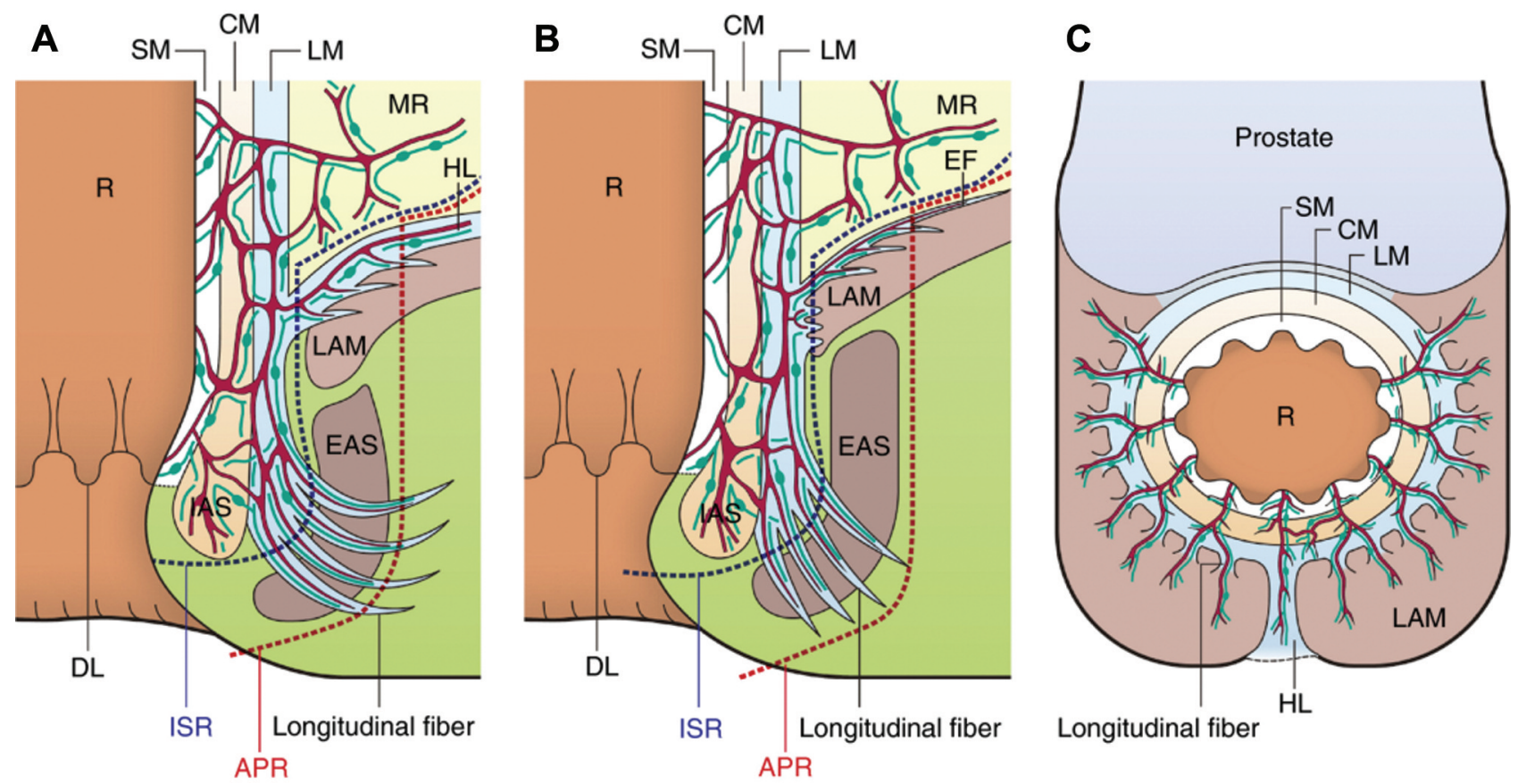

Figure 2. Schemas of lymphovascular flow around the anal canal. (A) Sagittal section of the posterior wall. (B) Frontal section of the lateral and anterolateral walls. (C) Axial section around the anal canal and LAM in a male cadaver. Communications between blood vessels (red solid lines) and initial lymphatics (green solid lines with round dots) from the LM to the HL; EF and longitudinal fibres are demonstrated. Resection lines of ISR (blue dotted line) and standard APR (red dotted line) are shown in (A) and (B). APR, Abdominoperineal resection; CM, circular muscle; DL, dentate line; EAS, external anal sphincter; EF, endopelvic fascia; HL, hiatal ligament; IAS, internal anal sphincter; ISR, intersphincteric resection; LAM, levator ani muscle; LM, longitudinal muscle; MR, mesorectum; R, rectum; SM, submucosa. Figures are cited from (21). 
We suggest that future research should include a combination of ICG-FI and histological examination using fresh cadavers. Although these methods have not been used to examine the anorectal region in previous studies, they have been used to examine superficial lymphatics in fresh cadavers (59). We believe that these methods can be used to observe functional lymph flow in the anorectal region in detail. A notable region of interest of functional lymphatic flow around the anorectal region is the region from the lower rectum to the inguinal region because tumour invasion of the dentate line and lymphovascular tumour invasion are considered risk factors for inguinal lymph node metastasis $(60,61)$. However, microanatomical inguinal lymph node metastatic pathways have not been reported in anorectal lesions. The lymphatic system around the DVF is also an important region of interest because low rectal cancer in the anterior portion has poor oncological outcomes (62).

\section{Conclusion}

This review summarized the fascial structures and lymphovascular network around the pelvic floor. Lymphatic flow between rectal muscle fibres, HL, and $\mathrm{EF}$ are suggested. The results provide important information to discuss therapeutic strategies for low rectal cancer. Existence of widespread lymphovascular network around the pelvic floor suggests that only conventional surgical treatment may not improve oncological outcomes because the network exceeds the resection lines of conventional APR and ISR. Therefore, enlarging the resection area of APR to include the EF and HL within the resection area, or introducing preoperative therapy seem to be effective.

Although the lymphatic systems of the pelvic region remain unclear, our novel findings help researchers analyse this complex area (21). The analysed methodology may be applied to other areas in the pelvis and may contribute to future research. There are many regions of interest for analysing functional lymphovascular networks in the pelvis, and continuous research is expected to take place.

\section{Conflicts of Interest}

The Authors declare no conflicts of interest.

\section{Authors' Contributions}

Kentaro Sato, Takuya Miura, Yoshiyuki Sakamoto, Hajime Morohashi, and Kenichi Hakamada contributed to the study concept and design. Kentaro Sato wrote the paper and prepared original draft. Takuya Miura, Yoshiyuki Sakamoto, Hajime Morohashi, and Kenichi Hakamada reviewed and edited the manuscript. Kenichi Hakamada supervised the study. All Authors read and approved the final manuscript.

\section{Acknowledgements}

The Authors thank Drs. Hiroshi Shimoda, Seiji Watanabe, Hirokazu Narita, and Kazuto Takahashi (Department of Anatomical Science, Hirosaki University Graduate School of Medicine, Hirosaki, Aomori, Japan); Drs. Yoshiya Asano, Daisuke Okano, and Erina Saito (Department of Neuroanatomy, Cell Biology, Histology, Hirosaki University Graduate School of Medicine, Hirosaki, Aomori, Japan); and Drs. Takuji Kagiya, Yuto Mitsuhashi, and Kotaro Umemura (Department of Gastroenterological Surgery, Hirosaki University Graduate School of Medicine, Hirosaki, Aomori, Japan) for their assistance with tissue sectioning, tissue staining, and immunohistochemistry. The authors also thank Drs. Yuichiro Tsukada (Department of Colorectal Surgery, National Cancer Center Hospital East, Chiba, Japan) and Ken Imaizumi (Department of Gastroenterological Surgery, Hakodate Municipal Hospital, Hakodate, Hokkaido, Japan) for their discussions regarding the clinical anatomy of the pelvic floor.

This study was supported by the Japanese Society for the Promotion of Science KAKENHI [grant number 18K16295, Grantin-Aid for Young Scientists (B)]. No additional external funding was received for this study.

\section{References}

1 Blair JB, Holyoke EA and Best RR: A note on the lymphatics of the middle and lower rectum and anus. Anat Rec 108(4): 635644, 1950. PMID: 14799884. DOI: 10.1002/ar.1091080402

2 Shafik A: Levator ani muscle: new physioanatomical aspects and role in the micturition mechanism. World J Urol 17(5): 266-273, 1999. PMID: 10552142. DOI: 10.1007/s003450050144

3 Kinugasa Y, Arakawa T, Abe S, Ohtsuka A, Suzuki D, Murakami G, Fujimiya M and Sugihara K: Anatomical reevaluation of the anococcygeal ligament and its surgical relevance. Dis Colon Rectum 54(2): 232-237, 2011. PMID: 21228674. DOI: 10.1007/DCR.0b013e318202388f

4 Muro S, Yamaguchi K, Nakajima Y, Watanabe K, Harada M, Nimura A and Akita K: Dynamic intersection of the longitudinal muscle and external anal sphincter in the layered structure of the anal canal posterior wall. Surg Radiol Anat 36(6): 551-559, 2014. PMID: 24258358. DOI: $10.1007 / \mathrm{s} 00276-013-1228-8$

5 Macchi V, Porzionato A, Stecco C, Vigato E, Parenti A and De Caro R: Histo-topographic study of the longitudinal anal muscle. Clin Anat 21(5): 447-452, 2008. PMID: 18561297. DOI: 10.1002/ca.20633

6 Arakawa T, Murakami G, Nakajima F, Matsubara A, Ohtsuka A, Goto $\mathrm{T}$ and Teramoto T: Morphologies of the interfaces between the levator ani muscle and pelvic viscera, with special reference to muscle insertion into the anorectum in elderly Japanese. Anat Sci Int 79(2): 72-81, 2004. PMID: 15218626. DOI: 10.1111/j.1447-073x.2004.00069.x

7 Tsukada Y, Ito M, Watanabe K, Yamaguchi K, Kojima M, Hayashi R, Akita K and Saito N: Topographic anatomy of the anal sphincter complex and levator ani muscle as it relates to intersphincteric resection for very low rectal disease. Dis Colon Rectum 59(5): 426-433, 2016. PMID: 27050605. DOI: 10.1097/DCR.0000000000000565

8 Kim JH, Kinugasa Y, Hwang SE, Murakami G, RodríguezVázquez JF and Cho BH: Denonvilliers' fascia revisited. Surg Radiol Anat 37(2): 187-197, 2015. PMID: 25008480. DOI: 10.1007/s00276-014-1336-0 
9 Kraima AC, West NP, Treanor D, Magee DR, Rutten HJ, Quirke P, DeRuiter MC and van de Velde CJ: Whole mount microscopic sections reveal that Denonvilliers' fascia is one entity and adherent to the mesorectal fascia; implications for the anterior plane in total mesorectal excision? Eur J Surg Oncol 41(6): 738745, 2015. PMID: 25892592. DOI: 10.1016/j.ejso.2015.03.224

10 Law WL and Chu KW: Abdominoperineal resection is associated with poor oncological outcome. Br J Surg 91(11): 1493-1499, 2004. PMID: 15455362. DOI: 10.1002/bjs.4723

11 Shihab OC, Brown G, Daniels IR, Heald RJ, Quirke P and Moran BJ: Patients with low rectal cancer treated by abdominoperineal excision have worse tumors and higher involved margin rates compared with patients treated by anterior resection. Dis Colon Rectum 53(1): 53-56, 2010. PMID: 20010351. DOI: 10.1007/DCR.0b013e3181c70465

12 Holm T, Ljung A, Häggmark T, Jurell $\mathrm{G}$ and Lagergren J: Extended abdominoperineal resection with gluteus maximus flap reconstruction of the pelvic floor for rectal cancer. Br J Surg 94(2): 232-238, 2007. PMID: 17143848. DOI: $10.1002 /$ bjs. 5489

13 Sakamoto Y, Morohashi H, Miura T, Tsutsumi S, Takahashi S, Hirama K, Wakiya $\mathrm{T}$ and Hakamada K: A Prospective multicenter phase II study on the feasibility and efficacy of S-1 and oxaliplatin neoadjuvant chemotherapy for locally advanced rectal cancer. Dis Colon Rectum, 2021. PMID: 33833145. DOI: 10.1097/DCR.0000000000001927

14 Bosset JF, Collette L, Calais G, Mineur L, Maingon P, RadosevicJelic L, Daban A, Bardet E, Beny A, Ollier JC and EORTC Radiotherapy Group Trial 22921: Chemotherapy with preoperative radiotherapy in rectal cancer. N Engl J Med 355(11): 1114-1123, 2006. PMID: 16971718. DOI: 10.1056/NEJMoa060829

15 Yamashita K, Matsuda T, Hasegawa H, Mukohyama J, Arimoto A, Tanaka T, Yamamoto M, Matsuda Y, Kanaji S, Nakamura T, Sumi Y, Suzuki S and Kakeji Y: Recent advances of neoadjuvant chemoradiotherapy in rectal cancer: Future treatment perspectives. Ann Gastroenterol Surg 3(1): 24-33, 2018. PMID: 30697607. DOI: $10.1002 /$ ags 3.12213

16 Miura T, Sakamoto Y, Morohashi H, Yoshida T, Sato K and Hakamada K: Risk factor for permanent stoma and incontinence quality of life after sphincter-preserving surgery for low rectal cancer without a diverting stoma. Ann Gastroenterol Surg 2(1): 79-86, 2017. PMID: 29863122. DOI: 10.1002/ags3.12033

17 Garcia-Aguilar J, Mellgren A, Sirivongs P, Buie D, Madoff RD and Rothenberger DA: Local excision of rectal cancer without adjuvant therapy: a word of caution. Ann Surg 231(3): 345-351, 2000. PMID: 10714627. DOI: 10.1097/00000658-20000300000007

18 Mellgren A, Sirivongs P, Rothenberger DA, Madoff RD and García-Aguilar J: Is local excision adequate therapy for early rectal cancer? Dis Colon Rectum 43(8): 1064-71; discussion 1071-4, 2000. PMID: 10950004. DOI: 10.1007/BF02236551

19 Sasaki T, Ito Y, Ohue M, Kanemitsu Y, Kobatake T, Ito M, Moriya $\mathrm{Y}$ and Saito N: Postoperative chemoradiotherapy after local resection for high-risk T1 to T2 low rectal cancer: Results of a single-arm, multi-institutional, phase II clinical trial. Dis Colon Rectum 60(9): 914-921, 2017. PMID: 28796729. DOI: 10.1097/DCR.0000000000000870

20 Devane LA, Burke JP, Kelly JJ and Albert MR: Transanal minimally invasive surgery for rectal cancer. Ann Gastroenterol Surg 5(1): 3945, 2020. PMID: 33532679. DOI: 10.1002/ags3.12402
21 Sato K, Shimoda H, Miura T, Sakamoto Y, Morohashi H, Watanabe S, Narita H, Mitsuhashi Y, Umemura K and Hakamada K: Widespread anorectal lymphovascular networks and tissue drainage: analyses from submucosal India ink injection and indocyanine green fluorescence imaging. Colorectal Dis 23(6): 1334-1345, 2021. PMID: 33570769. DOI: 10.1111/codi.15582

22 Raychaudhuri B and Cahill D: Pelvic fasciae in urology. Ann R Coll Surg Engl 90(8): 633-637, 2008. PMID: 18828961. DOI: 10.1308/003588408X321611

23 Wimpissinger TF, Tschabitscher M, Feichtinger H and Stackl W: Surgical anatomy of the puboprostatic complex with special reference to radical perineal prostatectomy. BJU Int 92(7): 681684, 2003. PMID: 14616445. DOI: $10.1046 / \mathrm{j} .1464-$ 410x.2003.04489.x

24 Takenaka A, Hara R, Soga H, Murakami G and Fujisawa M: A novel technique for approaching the endopelvic fascia in retropubic radical prostatectomy, based on an anatomical study of fixed and fresh cadavers. BJU Int 95(6): 766-771, 2005. PMID: 15794779. DOI: 10.1111/j.1464-410X.2005.05397.x

25 Cör A, Barbic M and Kralj B: Differences in the quantity of elastic fibres and collagen type I and type III in endopelvic fascia between women with stress urinary incontinence and controls. Urol Res 31(2): 61-65, 2003. PMID: 12677309. DOI: 10.1007/s00240-002-0293-y

26 Charran O, Muhleman M, Shoja MM, Tubbs RS and Loukas M: Charles-Pierre Denonvilliers (1808-1872): renowned anatomist, plastic surgeon, and influential member of French society. Clin Anat 26(7): 788-792, 2013. PMID: 22576975. DOI: $10.1002 /$ ca.22092

27 Bertrand MM, Alsaid B, Droupy S, Benoit G and Prudhomme M: Biomechanical origin of the Denonvilliers' fascia. Surg Radiol Anat 36(1): 71-78, 2014. PMID: 23732391. DOI: 10.1007/s00276-013-1142-0

28 Richardson AC: The rectovaginal septum revisited: its relationship to rectocele and its importance in rectocele repair. Clin Obstet Gynecol 36(4): 976-983, 1993. PMID: 8293598. DOI: $10.1097 / 00003081-199312000-00022$

29 Tobin CE and Benjamin JA: Anatomical and surgical restudy of Denonvilliers's fascia. Surg Gynecol Obstet 80(4): 373-388, 1945.

30 Kinugasa Y, Murakami G, Uchimoto K, Takenaka A, Yajima T and Sugihara K: Operating behind Denonvilliers' fascia for reliable preservation of urogenital autonomic nerves in total mesorectal excision: a histologic study using cadaveric specimens, including a surgical experiment using fresh cadaveric models. Dis Colon Rectum 49(7): 1024-1032, 2006. PMID: 16732487. DOI: 10.1007/s10350-006-0557-7

31 Takahashi T, Ueno M, Azekura K and Ohta H: Lateral ligament: its anatomy and clinical importance. Semin Surg Oncol 19(4): 386-395, 2000. PMID: 11241921. DOI: $10.1002 /$ ssu.9

32 Jones OM, Smeulders N, Wiseman O and Miller R: Lateral ligaments of the rectum: an anatomical study. Br J Surg 86(4): 487-489, 1999. PMID: 10215819. DOI: 10.1046/j.13652168.1999.01080.x

33 Wang GJ, Gao CF, Wei D, Wang C and Meng WJ: Anatomy of the lateral ligaments of the rectum: a controversial point of view. World J Gastroenterol 16(43): 5411-5415, 2010. PMID: 21086557. DOI: $10.3748 / w j g . v 16 . i 43.5411$

34 Goligher JC: Colon, rectum, and anus - surgical. Med Annu 78: 40-53, 1960. PMID: 13706697. 
35 Sato K and Sato T: The vascular and neuronal composition of the lateral ligament of the rectum and the rectosacral fascia. Surg Radiol Anat 13(1): 17-22, 1991. PMID: 2053040. DOI: 10.1007/BF01623135

36 Pak-art R, Tansatit T, Mingmalairaks C, Pattana-arun J, Tansatit $\mathrm{M}$ and Vajrabukka T: The location and contents of the lateral ligaments of the rectum: a study in human soft cadavers. Dis Colon Rectum 48(10): 1941-1944, 2005. PMID: 16175322. DOI: $10.1007 / \mathrm{s} 10350-005-0156-\mathrm{Z}$

37 Yanagita S, Uenosono Y, Arigami T, Kita Y, Mori S and Natsugoe S: Utility of the sentinel node concept for detection of lateral pelvic lymph node metastasis in lower rectal cancer. BMC Cancer 17(1): 433, 2017. PMID: 28629335. DOI: 10.1186/s12885-017-3408-0

38 Jamieson JK and Dobson JF: On the injection of lymphatics by Prussian blue. J Anat Physiol 45(Pt 1): 7-10, 1910. PMID: 17232866.

39 Fu KI, Fujii T, Kato S, Sano Y, Koba I, Mera K, Saito H, Yoshino T, Sugito M and Yoshida S: A new endoscopic tattooing technique for identifying the location of colonic lesions during laparoscopic surgery: a comparison with the conventional technique. Endoscopy 33(8): 687-691, 2001. PMID: 11490385. DOI: $10.1055 / \mathrm{s}-2001-16217$

40 Milone M, Vignali A, Manigrasso M, Velotti N, Sarnelli G, Aprea G, De Simone G, Maione F, Gennarelli N, Elmore U and De Palma GD: Sterile carbon particle suspension vs India ink for endoscopic tattooing of colonic lesions: a randomized controlled trial. Tech Coloproctol 23(11): 1073-1078, 2019. PMID: 31667693. DOI: 10.1007/s10151-019-02101-y

41 Dawson K, Wiebusch A and Thirlby RC: Preoperative tattooing and improved lymph node retrieval rates from colectomy specimens in patients with colorectal cancers. Arch Surg 145(9): 826-830, 2010. PMID: 20855751. DOI: 10.1001/archsurg.2010.180

42 Bartels SA, van der Zaag ES, Dekker E, Buskens CJ and Bemelman WA: The effect of colonoscopic tattooing on lymph node retrieval and sentinel lymph node mapping. Gastrointest Endosc 76(4): 793-800, 2012. PMID: 22835497. DOI: 10.1016/j.gie.2012.05.005

43 Liu P, Tan J, Tan Q, Xu L, He T and Lv Q: Application of carbon nanoparticles in tracing lymph nodes and locating tumors in colorectal cancer: a concise review. Int $\mathrm{J}$ Nanomedicine 15: 9671-9681, 2020. PMID: 33293812. DOI: 10.2147/IJN.S281914

44 Gao Z, Ye Y, Zhang W, Shen D, Zhong Y, Jiang K, Yang X, Yin M, Liang B, Tian $L$ and Wang $S$ : An anatomical, histopathological, and molecular biological function study of the fascias posterior to the interperitoneal colon and its associated mesocolon: their relevance to colonic surgery. J Anat 223(2): 123-132, 2013. PMID: 23721400. DOI: 10.1111/joa.12066

45 Block IR: A more radical perineal phase for abdominoperineal resection of rectum for carcinoma. Surg Gynecol Obstet 107(5): 667-671, 1958. PMID: 13592670.

46 Kumashiro R, Sano C, Sakai T, Ugaeri H, Madokoro S, Yamazaki S, Inutsuka $\mathrm{S}$ and Takahashi $\mathrm{T}$ : Radical lymphadenectomy for rectal cancer facilitated by a carbon particle infusion lymphangiography. Surg Today 22(6): 512-516, 1992. PMID: 1282054. DOI: 10.1007/BF00308896

47 Bartholdson L, Hultborn A, Hultén L, Roos B, Rosencrantz M and Ahrén C: Lymph drainage from the upper and middle third of the rectum as demonstrated by $198 \mathrm{Au}$. Acta Radiol Ther Phys Biol
16(4): 352-360, 1977. PMID: 930639. DOI: 10.3109/028418677 09133955

48 Takemura K, Ando M, Okabe S, Wakayama H, Jin K, Ishii K, Kaneko Y and Endo M: Lymphatic drainage from the lower rectum. Nippon Daicho Komonbyo Gakkai Zasshi 39(2): 113120, 2021. DOI: 10.3862/jcoloproctology.39.113

49 Funahashi K, Koike J, Shimada M, Okamoto K, Goto T and Teramoto T: A preliminary study of the draining lymph node basin in advanced lower rectal cancer using a radioactive tracer. Dis Colon Rectum 49(10 Suppl): S53-S58, 2006. PMID: 17106816. DOI: 10.1007/s10350-006-0659-2

50 Emile SH, Elfeki H, Shalaby M, Sakr A, Sileri P, Laurberg S and Wexner SD: Sensitivity and specificity of indocyanine green near-infrared fluorescence imaging in detection of metastatic lymph nodes in colorectal cancer: Systematic review and metaanalysis. J Surg Oncol 116(6): 730-740, 2017. PMID: 28570748. DOI: $10.1002 /$ jso.24701

51 Liberale G, Vankerckhove S, Caldon MG, Ahmed B, Moreau M, Nakadi IE, Larsimont D, Donckier V, Bourgeois P and Group R\&D for the Clinical Application of Fluorescence Imaging of the Jules Bordet's Institute: Fluorescence imaging after indocyanine green injection for detection of peritoneal metastases in patients undergoing cytoreductive surgery for peritoneal carcinomatosis from colorectal cancer: a pilot study. Ann Surg 264(6): 1110-1115, 2016. PMID: 27828822. DOI: 10.1097/SLA.0000000000001618

52 Watanabe J, Ota M, Suwa Y, Ishibe A, Masui H and Nagahori $\mathrm{K}$ : Evaluation of lymph flow patterns in splenic flexural colon cancers using laparoscopic real-time indocyanine green fluorescence imaging. Int J Colorectal Dis 32(2): 201-207, 2017. PMID: 27695977. DOI: 10.1007/s00384-016-2669-4

53 Nagata K, Endo S, Hidaka E, Tanaka J, Kudo SE and Shiokawa A: Laparoscopic sentinel node mapping for colorectal cancer using infrared ray laparoscopy. Anticancer Res 26(3B): 23072311, 2006. PMID: 16821607.

54 Kusano M, Tajima Y, Yamazaki K, Kato M, Watanabe M and Miwa M: Sentinel node mapping guided by indocyanine green fluorescence imaging: a new method for sentinel node navigation surgery in gastrointestinal cancer. Dig Surg 25(2): 103-108, 2008. PMID: 18379188. DOI: 10.1159/000121905

55 Hutteman M, Choi HS, Mieog JS, van der Vorst JR, Ashitate Y, Kuppen PJ, van Groningen MC, Löwik CW, Smit VT, van de Velde CJ, Frangioni JV and Vahrmeijer AL: Clinical translation of ex vivo sentinel lymph node mapping for colorectal cancer using invisible near-infrared fluorescence light. Ann Surg Oncol 18(4): 1006-1014, 2011. PMID: 21080086. DOI: 10.1245/s10434-010$1426-0$

56 Noura S, Ohue M, Seki Y, Tanaka K, Motoori M, Kishi K, Miyashiro I, Ohigashi H, Yano M, Ishikawa O and Miyamoto Y: Feasibility of a lateral region sentinel node biopsy of lower rectal cancer guided by indocyanine green using a near-infrared camera system. Ann Surg Oncol 17(1): 144-151, 2010. PMID: 19774415. DOI: 10.1245/s10434-009-0711-2

57 Zhou SC, Tian YT, Wang XW, Zhao CD, Ma S, Jiang J, Li EN, Zhou HT, Liu Q, Liang JW, Zhou ZX and Wang XS: Application of indocyanine green-enhanced near-infrared fluorescence-guided imaging in laparoscopic lateral pelvic lymph node dissection for middle-low rectal cancer. World $\mathbf{J}$ Gastroenterol 25(31): 4502-4511, 2019. PMID: 31496628. DOI: $10.3748 /$ wjg.v25.i31.4502 
58 Denost Q, Adam JP, Rullier A, Buscail E, Laurent C and Rullier E: Perineal transanal approach: a new standard for laparoscopic sphincter-saving resection in low rectal cancer, a randomized trial. Ann Surg 260(6): 993-999, 2014. PMID: 24950270. DOI: 10.1097/SLA.0000000000000766

59 Shinaoka A, Koshimune S, Yamada K, Kumagishi K, Suami H, Kimata Y and Ohtsuka A: A fresh cadaver study on indocyanine green fluorescence lymphography: a new whole-body imaging technique for investigating the superficial lymphatics. Plast Reconstr Surg 141(5): 1161-1164, 2018. PMID: 29334573. DOI: 10.1097/PRS.0000000000004315

60 Wang R, Wu P, Shi D, Zheng H, Huang L, Gu W, Xu Y, Cai S and Cai G: Risk factors of synchronous inguinal lymph nodes metastasis for lower rectal cancer involving the anal canal. PLoS One 9(11): e111770, 2014. PMID: 25409168. DOI: 10.1371/ journal.pone. 0111770
61 Shiratori H, Nozawa H, Kawai K, Hata K, Tanaka T, Kaneko M, Emoto S, Sonoda $\mathrm{H}$ and Ishihara S: Risk factors and therapeutic significance of inguinal lymph node metastasis in advanced lower rectal cancer. Int J Colorectal Dis 35(4): 655-664, 2020. PMID: 32009191. DOI: 10.1007/s00384-020-03520-2

62 den Dulk M, Marijnen CA, Putter H, Rutten HJ, Beets GL, Wiggers T, Nagtegaal ID and van de Velde CJ: Risk factors for adverse outcome in patients with rectal cancer treated with an abdominoperineal resection in the total mesorectal excision trial. Ann Surg 246(1): 83-90, 2007. PMID: 17592295. DOI: 10.1097/01.sla.0000259432.29056.9d

Received July 6, 2021

Revised July 26, 2021

Accepted August 25, 2021 